\title{
Do expenditures on tobacco control decrease smoking prevalence?
}

\author{
Michael L. Marlow \\ Economics, Business College, California Polytechnic State University, \\ San Luis Obispo, 93407 Unites States \\ E-mail:mmarlow@calpoly.edu
}

Effectiveness of tobacco control programmes in reducing smoking prevalence during 2001 to 2005 is examined. Tobacco control spending is found to exert no significant effects on smoking prevalence across the 50 states. Cigarette prices are found to lower prevalence of daily smokers, but exert no effect on nondaily smoking prevalence. Several reasons are suggested for why these results might conflict with previous research. These include that most previous studies examined two states (California and Massachusetts) with long-standing tobacco control programmes and that most studies examined periods in which many of the states in their samples did not actively fund their programmes. Another reason may be that, unlike most previous studies, this study controls for the possibility that tobacco control spending is endogenous when, for example, states exhibiting relatively low smoking prevalence are also states with relatively high distaste for smoking and accordingly fund tobacco control programmes more generously. A negative relation between tobacco control spending and smoking prevalence does not necessarily indicate that higher spending causes lower prevalence when spending is endogenously determined.

\section{Introduction}

Declines in smoking can be measured in both cigarette sales and smoking prevalence. U.S. taxed sales per capita have fallen $38 \%$, from 101 to 63 packs, over 1990 to $2005 .{ }^{1}$ Smoking prevalence of adults has fallen $18 \%$, from 25.5 to $20.9 \%$, over the same period. ${ }^{2}$ There is widespread agreement that declines in smoking are a result of greater health concerns regarding smoking and higher prices. Tax increases predictably lower smoking because sellers partially shift taxes onto smokers through higher prices. $^{3}$ State tax rates rose $176 \%$ over 1990 to 2005, from 29 to 80 cents (\$2003) and contributed to the $75 \%$ rise in prices, from $\$ 2.27$ to $\$ 3.98$ per pack (\$2003), over the same period. The Master Settlement Agreement can also be viewed as a tax increase that ultimately raised prices and contributed to less smoking. Keeler et al. (2004) argue that, while cigarette prices rose following the Tobacco Settlement of 1998, the drop in cigarette consumption was somewhat muted by subsequent increases in advertising by cigarette companies.

\footnotetext{
${ }^{1}$ Orzechowski and Walker (2005).

2 'Smoking Prevalence Among U.S. Adults,' October 2006; taken from http://www.cdc.gov/tobacco/research_data/ adults_prev/prevali.htm.

${ }^{3}$ For a recent study of how cigarette tax increases in Japan are predicted to effectively lower smoking, see Wan (2006).
} 
It remains less clear whether other public policies - smoking bans and tobacco control programmes - have lowered smoking. Bans on smoking in public places, such as in restaurants and workplaces, are more commonplace and they might change social norms regarding acceptability of smoking and cause some smokers to quit or lower consumption, or even cause fewer people to take up smoking. ${ }^{4}$ Smokers may also alter consumption during hours subject to bans, or by changing time and frequency spent in places subject to bans. Dunham and Marlow (2003) show that restaurant and bar owners alter prices, entertainment, hours of operation and other business attributes as well in response to smoking laws. Tauras (2006) finds that smoking bans do not significantly influence adult smoking prevalence. Tobacco control programmes fund activities such as education, smoking cessation help, enforcement of restricted sales to individuals (e.g. minors) or locations (e.g. hospitals, schools), counter-advertising and research on programme effectiveness. These activities potentially influence smoking in many different ways.

While studies have concluded that tobacco control programmes lower smoking, the present article argues that recent evidence sheds some doubt on this conclusion based on funding during 2001 to 2005 . Previous studies were mostly conducted on years prior to 2001, the first year in which publicly available data on these programmes became available and before many state programmes became actively funded. Many studies also focused on two states, California and Massachusetts, with the longest funding histories and so probably awarded undue bias to states that perceived smoking to be a relatively greater problem than other states, to states that could more effectively use public monies to lower smoking than other states or to more active and well-organized anti-smoking organizations. Our examination of recent data during periods with widespread funding of tobacco control programmes indicates that past results do not hold for the current environment of more actively funded tobacco control programmes.

\section{Tobacco Control Literature}

Studies of tobacco control programmes often focus on two states, California and Massachusetts, because these states have the longest funding histories for these programmes. Combined with Arizona and Oregon, these four states are argued by the Centers for Disease Control and Prevention (CDC) to exhibit the longest-lived programmes in tobacco control. ${ }^{5}$ California is often considered the best model for other state tobacco-control programmes due to its early adoption of comprehensive programmes that included tax increases, tobacco-control spending on health education and counter-advertising, and smoking bans in public places. Tobacco-control began in 1988 when voters approved the California Tobacco Tax and Health Promotion Act of 1988 (Proposition 99), which increased the state surtax on cigarettes by 25 cents per pack. Revenues from the new tax were earmarked for tobacco-related disease research, health education against tobacco and health care for medically indigent families. The authorizing legislation established the goal of reducing tobacco consumption by $75 \%$ in California by 1999 . Slightly over \$2 billion (\$2003) has been spent in California on tobacco-control over 1989 to 2002 , or roughly $\$ 62$ (\$2003) per capita over this period. ${ }^{6}$ California passed a statewide smoking ban in public places in 1994 that was fully implemented in $1998 .^{7}$

Massachusetts also has an active tobacco control programme. In 1992, a Massachusetts ballot initiative raised taxes 25 cents per pack that also raised revenues for creation of the Massachusetts Tobacco Control Program. Slightly over \$400 million (\$2003) has been spent in Massachusetts on tobacco control over 1994 to 2005, or roughly $\$ 5.50$ (\$2003) per capita on average over this period. ${ }^{8}$ In 2004, bans on smoking in all workplaces, restaurants and bars became effective throughout the state. ${ }^{9}$

Farrelly et al. (2003) argue that most studies of tobacco control programmes simply perform trend analysis surrounding introduction of new tobacco control programmes and ignore other factors that might influence tobacco consumption.

\footnotetext{
${ }^{4}$ Farrelly et al. (1999) estimates that smoking bans on all US workplaces would reduce smoking prevalence by $10 \%$. Lye and Hirschberg (2004) provide support for the view that governments may enhance worker productivity, and therefore wages, by regulating smoking and drinking. Boyes and Marlow (1996) find evidence of many smoke-free restaurants prior to passage of a smoking ban in one of the earliest cities in California to adopt such a ban and suggest that smoking bans may exert little or no effect on tobacco use if bans follow changes in smoking behaviour rather than cause such changes.

${ }_{6}^{5} \mathrm{CDC}(2001)$ and CDC (2002).

${ }^{6}$ Ibrahim and Glantz (2003). Per capita calculation computed by the author using average California population over this period.

${ }^{7}$ See American Nonsmokers' Rights Foundation (2006) for the list of local jurisdictions and their enactment dates.

${ }^{8}$ See Koh et al. (2005).

${ }^{9}$ See American Nonsmokers' Rights Foundation (2006) for the list of local jurisdictions and their enactment dates.
} 
Manley et al. (1997) concluded that sales fell in states participating in the ASSIST (American Stop Smoking Intervention Study) programme when compared to states not participating, but ignored other factors that might contribute to such a decline. Pierce et al. (1998) concluded that California control programmes significantly lowered tobacco use, but also did not control for other factors. Biener et al. (2000) compared cigarette consumption in Massachusetts with most other states and concluded that, because over 1988 to 1999 smoking fell much more in Massachusetts, it was the result of tobacco control programmes. Other possible factors were not considered. Weintraub and Hamilton (2002) tested for changes in linear time trends to determine whether smoking prevalence in Massachusetts differed from that of 41 other states over 1990 to 99 and, because declines in Massachusetts were greater, they attributed them to its tobacco control programme. Other possible contributing factors were not considered. Robbins et al., (2002) concluded that the 1995 to 1999 decline in smoking in Massachusetts was a result of tobacco control policies even though other factors were ignored. Soldz et al. (2002) concluded that because school prevalence survey in Massachusetts showed larger reductions than other states following tobacco control policies, policies were effective in prevalence. Koh et al. (2005) argued that, simply because cigarette consumption dropped nearly by half during the first decade of its tobacco control programme, the Massachusetts's programme was effective.

Unfortunately, these studies do not control for factors outside of public policies themselves such as smuggling, income and greater health concerns over time. ${ }^{10}$ Studies often do not even control for cigarette prices or taxes when they conclude that tobacco control programmes effectively lower tobacco consumption. Even if conclusions were valid, it remains questionable whether extrapolation onto other states is appropriate since characteristics of smokers, programme administrators, and other factors vary considerably across states. Despite the many studies supporting the effectiveness of tobacco control programmes in California and Massachusetts, conclusions are at most suggestive of policy effects on smoking.
Five studies so far control for one or more factors outside of tobacco control programmes. ${ }^{11} \mathrm{Hu}$ et al. (1995a) controlled for state excise taxes and tobacco firm media expenditures and found that state government counter-advertising lowered consumption in California. Hu et al. (1995b) estimated that a 25-cent state tax hike reduced taxed sales in California when measured over about 2 years. These studies controlled for effects of time on cigarette consumption which may control for various other factors, such as greater health concerns that affect smoking over time. However, these two studies focus on California, the longest-lived state programme, and examine effects on taxed sales over few, and early, years of a programme that began in 1988.

Farrelly et al. (2003) examined tobacco control activities of all 50 states and concluded that state tobacco control expenditures lowered taxed cigarette sales over 1981 to 2000 after controlling for excise taxes, smuggling, time and other state-specific factors. The authors collected data themselves on the activities of these programmes because publicly data was not available. The authors concluded that past and current tobacco control spending lowered current taxed sales in the 50 states. They also found similar conclusions when separately examining the four states with the longest histories of such programmes (Arizona, California, Massachusetts and Oregon). Data on the 46 other states were not separately considered. Tauras et al. (2005) concluded that spending on tobacco control programmes in the 50 states lowered youth smoking prevalence and the number of cigarettes smoked by smokers over 1991 to 2000, after controlling for other factors that might also influence sales.

While the two studies just discussed broadened examination of tobacco control programmes to include all states, they also apparently examined years in which many states did not actively fund programmes. CDC $(2001,2002)$ only began publishing public data on funding of tobacco control programmes starting in 2001, and has indicated that many states did not actively fund programmes in prior years. Many states apparently did not actively fund programmes until after settlement of the Master Settlement Agreement in 1998. Marlow (2006) has

\footnotetext{
${ }^{10}$ Luccasasen et al. (2005) argue that smuggling mitigates much of the health benefits of higher cigarette taxes. Tauras et al. (2007) find that smokeless tobacco products and cigarettes are economic complements in consumption and therefore policies that lower cigarette consumption will lower smokeless tobacco consumption as well.

${ }^{11}$ Tauras and Chaloupka (2004) find that, after controlling for many other factors, higher spending on tobacco control changes youth's attitudes and beliefs towards smoking. Pechmann and Reibling (2006) find that spending on antismoking advertisements lowers youths' smoking intentions as long as they focus on tobacco-related disease and suffering. However, counterindustry advertisements were not found to lower intentions. These studies are not included in this discussion because they focused on intentions rather than outcomes.
} 
examined tobacco control spending in the 50 states during 2001 and 2002 after controlling for prices, smuggling and other factors that might be expected to influence taxed cigarette sales. Spending on tobacco control did not systematically influence taxed sales over these 2 years. However, an additional dollar in the four states with long-standing programmes (Arizona, California, Massachusetts and Oregon) was found to lower taxed sales, but this effect did not exist in the other states as a group. In separate regressions, tobacco control spending was determined to exert no significant effects on youth smoking prevalence. Marlow's (2006) examination of years in which many states actively funded programmes thus indicates little or no support of previous findings that tobacco control programmes lower smoking.

Two recent studies of the determinants of tobacco control funding suggest further concerns over previous conclusions regarding effectiveness of programmes. Gross et al. (2002) study state tobacco control spending in 2001 and conclude that state health issues such as Medicaid expenditures and citizens lacking health insurance exert little effect on state spending on tobacco control. The authors conclude that states do not appear to be allocating dollars systematically to programmes aimed at lowering tobacco use. ${ }^{12}$ Marlow (2007) concludes that state spending on tobacco control in 2001 and 2002 is unrelated to smoking prevalence, because states with higher smoking prevalence do not spend more on tobacco control than states with lower prevalence.

What implications for our study might follow from recent studies that find no systematic link between state spending on tobacco control and smoking prevalence? Under a federalist system of state governments, it would appear that state officials should allocate more resources to states with higher prevalence because needs are presumably greater. ${ }^{13}$ This logic is similar to the prediction that cold weather states spend more on snow removal than warm climate states since that's where the snow is. If, however, states with higher prevalence do not fund more dollars than states with lower prevalence, it becomes less likely that cross-state examination should uncover an inverse relation between tobacco control funding and prevalence. Further investigation of the determinants of spending on tobacco control would appear useful to our understanding of how such spending might affect smoking within a crossstate analysis. It is also important to note that despite growing government involvement in health care, there is a literature that finds little support for the view that greater public spending has been a causal factor behind greater health in wealthy countries. ${ }^{14}$

This survey raises several important issues for our examination. Most studies do not control for other contributing factors when they examine effects of tobacco control programmes on smoking and therefore their findings do not clearly indicate the extent to which programmes contribute to changes in smoking. These studies also focus on California and Massachusetts programmes, the two states with the longest history of funding such programmes. Even if other contributing factors are controlled for, focus on these two states suggests a selectivity bias that makes extrapolation of results onto other states problematic. Only five studies control for factors outside of tobacco control programmes themselves, and most examine periods prior to significant funding of programmes that began in 2001. Of these five studies, only Tauras et al. (2005) and Marlow (2006) examine prevalence data, and these studies focus on youth prevalence. Finally, recent findings in Gross et al. (2003), Marlow (2006) and Marlow (2007) examine more recent data in which most states have active funding of programmes and suggest that tobacco control programmes might not have contributed to recent declines in smoking.

\section{Effects of Tobacco Control Funding on Smoking Prevalence}

This article's focus on smoking prevalence rather than taxed cigarette sales has several advantages. It allows separation of two groups of consumers, daily and nondaily smokers, thus allowing direct

\footnotetext{
${ }^{12}$ Stevenson and Shughart (2006) provide additional evidence that might suggest that tobacco control spending might not vary systematically across states. They find that monies awarded to states from the Master Settlement Agreement were not entirely based on the stated purposes of recovering health care costs attributable to smoking and funding of smokingprevention programs.

${ }^{13}$ Of course, an economically efficient allocation does not necessarily mean that states with high prevalence should spend more on control if, for instance, programmes are not equally effective or when states have heterogeneous policy objectives. Differences in demographics across states might also lead to spending differences across states under a 'rational needs' approach. For example, Yen (2005) finds that smoking falls with education, but older smokers consume more cigarettes than younger smokers, in the USA. Goel and Nelson (2005) find significant differences in tobacco consumption across age and gender as well in the USA.

${ }^{14}$ See, for example, Charmistha and Grabowski (2003).
} 
examination of whether programmes promote quitting and whether effects on these two groups vary systematically. Focus on prevalence data also diminishes problems related to smuggling and internet sales that distort data on taxed cigarette sales. Taxed sales over-estimate reductions in consumption in high-taxed states and underestimate reductions in low-taxed states. Stehr (2005) has estimated that over 1985 to 2001, 9.6\% of cigarettes consumed were purchased outside the definition of taxed sales. Distortions have probably risen with the advent of internet sales, especially given recent increases in excise taxes in various states that have raised incentives for smokers to search for lower-priced cigarettes outside of the definition of tax sales within their state. Similar distortions are unlikely to have affected prevalence data thus indicating an advantage to its use over taxed cigarette sales data when examining what effects follow from tobacco control programmes.

CDC (2006) collect and report 'four-level smoking status' data broken down into four possibilities: 'smoke everyday', 'smoke some days', 'former smokers' and 'never smokers'. Data are collected by the Behavioral Risk Factor Surveillance System (BRFSS) which is a state-based system of health surveys that collects information on health risk behaviours, preventive health practices and health care access primarily related to chronic disease and injury. Data are collected monthly in all 50 states and more than 350000 adults are interviewed each year in what the CDC states is the largest telephone health survey in the world. Our examination focuses on 'smoke everyday' and 'smoke some days' categories, which are respectively termed 'daily' and 'non-daily' for convenience. These two categories are also summed together, which the CDC refers to as 'smoking prevalence', to examine if this prevalence measure is also influenced by tobacco control spending. These data are available since 2000, but we examine data since 2001 since, as just discussed, this is the first year in which comprehensive state data on tobacco control spending is available. There are 249 observations, 50 for each of 5 years, with the exception of Hawaii in 2004.

Table 1 displays daily and nondaily prevalence of the adult population over 2001 to 2005 as collected by the CDC. ${ }^{15}$ Daily smokers averaged $17.1 \%$ of the adult population over this period, with significant reductions during the last two years: $16.1 \%$ (2004) and $15.6 \%$ (2005). Nondaily smokers averaged $5.3 \%$ of
Table 1. Descriptive statistics: smoking prevalence percent of adult population

\begin{tabular}{llll}
\hline & Daily & Nondaily & Daily + nondaily \\
\hline 2001 & $17.7^{\mathrm{c}} \%^{\mathrm{c}}$ & $5.6^{\mathrm{o}} \%^{\mathrm{a}}$ & $23.3^{\mathrm{b}}$ \\
2002 & $18.4^{\mathrm{a}}$ & $5.0^{\mathrm{a}}$ & $23.4^{\mathrm{b}}$ \\
2003 & $17.4^{\mathrm{b}}$ & $5.1^{\mathrm{b}}$ & $22.5^{\mathrm{b}}$ \\
2004 & $16.1^{\mathrm{b}}$ & 5.5 & $21.5^{\mathrm{c}}$ \\
2005 & $15.6^{\mathrm{a}}$ & 5.4 & $21.0^{\mathrm{a}}$ \\
Average & $17.1^{\mathrm{a}}$ & 5.3 & 22.4 \\
\hline
\end{tabular}

Note: ${ }^{\mathrm{a}, \mathrm{b}, \mathrm{c}}$ Significant (two-tailed test) at $1 \%, 5 \%$ and $10 \%$ levels, respectively, for test of equality of means between given year and average of all years.

population over this period and do not exhibit similar recent reductions. Data therefore indicate significant reduction in daily smokers during 2004 and 2005, but no recent changes in nondaily smokers. Daily + nondaily prevalence has significantly fallen during $2004(21.5 \%)$ and $2005(21.0 \%)$, when viewed against its average of $22.4 \%$ over this period.

The model in Equation 1 estimates effects of tobacco control programmes on smoking prevalence, holding constant other factors that might contribute to changes in prevalence. Prevalence is the CDCdefined 'daily' and 'nondaily' prevalence rates of the adult population, plus their sum which is simply referred to as 'smoking prevalence'. The $\log$ of prevalence is examined because this transformation raised $t$-values of most coefficients without altering results of our examination.

$$
\begin{aligned}
\text { PREVALENCE }_{\mathrm{i}}= & \&\left(\mathrm{PRICE}_{\mathrm{i}}, \mathrm{INCOME}_{\mathrm{i}},\right. \\
& \text { COLLEGE }_{\mathrm{i}}, \text { AGE }_{\mathrm{i}}, \quad(1) \leftarrow \\
& \text { UNEMPLOYMENT }_{\mathrm{i}}, \quad \\
& \text { MORMON } \left._{\mathrm{i}}, \text { CONTROL }_{\mathrm{i}}\right) \leftarrow
\end{aligned}
$$

Table 2 displays summary statistics of independent variables defined over 2001 to 2005 . PRICE $\mathrm{i}_{\mathrm{i}}$ is the real (\$2003) price per package of cigarettes in cents, as reported in Orzechowski and Walker (2006), and is expected to be inversely related to prevalence measures. The log of price is used, which is a common transformation for demand studies and, coupled with the $\log$ of prevalence, directly estimates price elasticities of prevalence. Estimation without the log transformation does not alter results.

$\mathrm{INCOME}_{\mathrm{i}}$ is defined as real $(\$ 2003)$ per capita personal income as published by the U.S. Department of Commerce. ${ }^{16}$ Its sign is ambiguous since, while cigarettes may be an income-elastic good

\footnotetext{
${ }^{15}$ Centers for Disease Control and Prevention (CDC). 'Behavioral Risk Factor Surveillance System Survey Data', Atlanta, Georgia: U.S. Department of Health and Human Services, Centers for Disease Control and Prevention, (2006).

${ }^{16}$ Source: Regional Economic Information System, Bureau of Economic Analysis, U.S. Department of Commerce http:// www.bea.gov/bea/regional/spi/spi_download.csv?table_id $=544846$.
} 
Table 2. Summary statistics of independent variables, 2001 to 2005

\begin{tabular}{lcrrr}
\hline & Mean & SD & Minimum & Maximum \\
\hline PRICE (\$2003 cents per pack) & 400.72 & 60.95 & 324.09 & 605.83 \\
INCOME (\$2003 per capita) & 30695.85 & 4441.99 & 22798.55 & 44786.99 \\
BACHELOR's (Degrees, \% Adult Population) & 26.2 & 4.75 & 15.1 & 37.6 \\
AGE (Median) & 36.23 & 2.12 & 27.17 & 2.80 \\
UNEMPLOYMENT & 5.10 & 1.08 & 0.20 & 8.20 \\
MORMON (\% Population) & 2.63 & 8.41 & 5.00 & 11.85 \\
SPENDING (\$2003 per capita) & 2.87 & 2.65 & 00 \\
\hline
\end{tabular}

which indicates a positive sign, higher income individuals may also smoke less if they exhibit greater health concerns over smoking thus suggesting a negative sign. Reinhardt and Giles (2001) find that cigarette demand in Canada is extremely insensitive to income changes. COLLEGE $\mathrm{C}_{\mathrm{i}}$ is the percentage of the population aged 25 and over with a bachelor's degree. Its expected sign is negative because higher educated individuals are believed to smoke less than those less educated. Data are obtained from the U.S. Census. ${ }^{17}$ Yuanliang and Zongyi (2005) study Chinese cigarette demand and find that regional cigarette demand increases with educational level in the region. Madden (2007) examined factors influencing starting and quitting smoking for a sample of Irish women using duration analysis and conclude that taxation appears to be most effective in encouraging quitting for those with the least education.

$\mathrm{AGE}_{\mathrm{i}}$ is the median age of the population and is expected to exhibit a positive influence on prevalence based on conventional wisdom that older smokers exhibit greater preferences towards smoking than younger smokers. Goel and Nelson (2005) examine state-level data in 1997 and find significant differences in tobacco use across gender and age. Yen (2005) finds that, while older individuals are less likely to smoke, they do tend to consume more cigarettes than younger smokers when they continue to smoke. Data are obtained from the U.S. census. ${ }^{18}$

The unemployment rate UNEMPLOYMENT ${ }_{i}$ comes from U.S. Bureau of Labor Statistics and its effect on prevalence is ambiguous because higher values may cause more smoking due to greater anxiety over job loss, or higher values may lead to reduced prevalence due to fewer jobs. The percentage of the population that is Mormon $\left(\mathrm{Momon}_{\mathrm{i}}\right)$ controls for a population group that strongly discourages smoking among its disciples and is expected to be negatively related to prevalence. This measure is obtained from data complied by Professor John Green of the University of Akron. ${ }^{19}$

Finally, CONTROL $\mathrm{C}_{\mathrm{i}}$ is per capita real (\$2003) state spending on tobacco control and is commonly expected to be inversely related to smoking prevalence. Previous discussion indicated that, while many studies find this effect, such studies examine periods in which many states did not actively fund programmes and/or examined either California or Massachusetts programmes which were early pioneers of such programmes. More recent evidence suggests some doubt that such programmes lower smoking, either because they fail to show that higher funding lowers smoking or because cross-state funding differences do not appear to be related to differences in smoking prevalence. Table 3 displays summary statistics on state funding of tobacco control over 2001 to 2005, the same period in which daily and nondaily smoking prevalence data are available. Data are from CDC as neatly summarized on the website of the Campaign for Tobacco-Free Kids. ${ }^{20}$ Funding averaged \$2.87 (\$2003) per capita over 2001 to 2005, with an average range of $\$ 0$ to $\$ 11.85$.

Funding in years prior to 2001 could exert effects on prevalence in later years, as found in Farrelly et al. (2003). They concluded that contemporaneous and lagged funding lowered taxed cigarette sales over 1981 to 2000. Interestingly, contemporaneous and lagged values of spending were found to exert fairly similar effects on taxed cigarette sales, which might suggest that lack of data prior to 2001 may not prevent a conclusion that tobacco control programmes lower smoking over 2001 to 2005, if indeed this is true. Following Marlow (2006),

\footnotetext{
${ }^{17}$ Source: http://www.census.gov/population/socdemo/education/cps2005/tab13.xls

${ }^{18}$ Source: http://www.census.gov/popest/states/asrh/SC-EST2005-02.html

${ }^{19} 2004$ National Surveys of Religion and Politics, 2001 American Religious Identification Survey, 2000 Glenmary Religious Congregations and Membership in the U.S., United States Census, and 2002 Gallup Polls; see http://www.beliefnet.com/ politics/religiousaffiliation.html

${ }^{20}$ See www.tobaccofreekids.org, 'History of State Spending for Tobacco Prevention', 7 December 2005.
} 
Table 3. Descriptive statistics: tobacco control expenditures per capita (\$2003)

\begin{tabular}{lllll}
\hline & Mean & Median & Minimum & Maximum \\
\hline 2001 & $\$ 2.53$ & $\$ 1.66$ & $\$ 0$ & $\$ 10.38$ \\
2002 & 2.56 & 1.78 & $\$ 0$ & 11.85 \\
2003 & 3.02 & 2.58 & $\$ 0$ & 11.64 \\
2004 & 3.08 & 2.90 & $\$ 0$ & 10.90 \\
2005 & 3.16 & 2.42 & $\$ 0$ & 11.26 \\
Average & 2.87 & 2.32 & $\$ 0$ & 11.85 \\
\hline
\end{tabular}

we control for past spending in the four states (Arizona, California, Massachusetts and Oregon) known to have relatively long-lived and active programmes by creating a dichotomous variable for these four states. ${ }^{21}$ DUM4 equals 1 for these states and equals 0 otherwise. Both intercept and slope spending dummies are considered to examine whether effects of spending on smoking prevalence differ in these four states when compared to states without long and active funding histories prior to 2001.

Laws on smoking in public places represent other public policies that attempt to lower smoking. Laws vary considerably across states. The American Lung Association ranks states by laws ensuring smoke-free air and, in 2003, provided three states (California, Delaware and New York) with a grade of 'A', seven states a 'B' grade, four states a ' $C$ ' grade and all others grades of ' $F$ '. ${ }^{22}$ Following Farrelly et al. (2003) and Marlow (2006), such laws are considered goals of tobacco control programmes rather than tools, thus allowing tobacco control expenditures to reflect a comprehensive array of tobacco-control programme characteristics.

\section{Estimates of Effects of Tobacco Control Spending on Prevalence}

Endogeneity would be a concern when states with the greatest distaste for smoking were also states that fund tobacco control the most. It is possible, for example, that states exhibiting relatively few smokers are also states with relatively high distaste for smoking and, as a result of this connection, states that allocate many resources towards tobacco control may also have the fewest smokers. If true, a negative effect on smoking prevalence from tobacco control may not necessarily be caused by higher tobacco control funding. That is, many of these states would have relatively low smoking prevalence with or without funding much tobacco control and empirical testing would not clearly determine effects of tobacco control on smoking prevalence. Of course, higher tobacco control funding could simply cause lower smoking propensity, but we need to be careful to control for endogeneity in our empirical work.

Instrumental variable estimation is one method of dealing with endogeneity and involves selection of a new variable which is both highly correlated with the independent variable in question $\left(\mathrm{SPENDING}_{\mathrm{i}}\right)$ and also uncorrelated with the error term in the equation. Real (\$2003) state per capita tobacco settlement funds $\mathrm{TS}_{\mathrm{i}}$ are used as an instrument for SPENDING since these funds should influence funding availability for tobacco control, but there is little reason to believe that these funds independently influence smoking propensity. ${ }^{23}$ State spending on tobacco control programmes comes from a variety of sources. In 2002, for instance, 46 states received more than $\$ 6$ billion in tobacco settlement revenues (Master Settlement Agreement), and the four states (Florida, Minnesota, Mississippi and Texas) that settled independently with the tobacco industry also received substantial revenue. ${ }^{24}$ Settlement revenues were based on a formula that included smoking-attributable state Medicaid expenses. The Master Settlement Agreement did not dictate how funds were to be allocated, although the public health community had hoped that states would significantly expand funding of tobacco control programmes. Recent evidence, however, indicates that some of these dollars have gone towards closing state government deficits and costs associated with general health care programmes. ${ }^{25}$ Tobacco settlement data are obtained from Orzechowski and Walker (2006).

\footnotetext{
${ }^{21}$ Farrelly et al (2003) ran separate regressions on these four states along with their examinations of all states together. However, regressions were not run on the 46 states without long histories of active funding.

${ }^{22} \mathrm{http}$ ///lungaction.org/reports/key304.html

${ }^{23}$ Percent of voting-age population voting for Presidential candidates was considered as an alternative instrument. It was hypothesized that higher percents would indicate states with more citizens comfortable with attempting to lower smoking through tobacco control programmes, but, at the same time, there is no reason to expect that this percent would directly cause smoking prevalence. Percents for elections in 2000 were used for years 2001 and 2002, while percents in the 2004 election were used in each of remaining years and were obtained from the U.S. Statistical Abstract (2007). While the coefficient on the percent voting in Presidential elections was positive, it was significant at the $5 \%$ level and therefore believed to be inferior to tobacco settlement funds as an instrument which was significant at the $1 \%$ level.

${ }^{24}$ See GAO (2004).

${ }^{25}$ See, for example, Gross et al. (2002), Johnson (2004) and Sloan (2005).
} 
Simple correlation coefficients between $\mathrm{TS}_{\mathrm{i}}$ and all three measures of smoking propensity are 0.14 (daily), 0.00 (nondaily) and 0.13 (daily + nondaily), thus indicating little correlation between the instrumental variable and dependent variables. The firststage regression involves regressing all independent variables (except SPENDING ${ }_{i}$ ) plus the instrument $\left(\mathrm{TS}_{\mathrm{i}}\right)$ against SPENDING. Significant influences (sign, significance level) are found for PRICE $_{\mathrm{i}}$

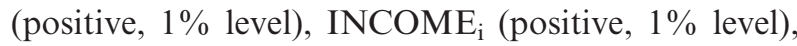
UNEMPLOYMENT $_{\mathrm{i}}$ (negative, $10 \%$ level) and $\mathrm{TS}_{\mathrm{i}}$ (positive, $1 \%$ level). ${ }^{26}$ Coefficients on COLLEGE $_{\mathrm{i}}$, $\mathrm{AGE}_{\mathrm{i}}, \mathrm{MORMON}_{\mathrm{i}}$ and dummies for years 2002, 2003, 2004 and 2005 are never significantly different from zero. The coefficient on $\mathrm{TS}_{\mathrm{i}}$ is 0.08 and indicates that tobacco control funding rises by $\$ 0.08$ for every $\$ 1.00$ increase in per capita tobacco settlement funding. The first-stage $F$-statistic on all right-handvariables equals 5.40. As a check for whether $\mathrm{TS}_{\mathrm{i}}$ is a weak instrument, one simple rule of thumb is to demonstrate that the $F$-statistic exceeds 10 when testing the hypothesis that the coefficients on all instruments are all zero. ${ }^{27} \mathrm{In}$ this case, an $\mathrm{F}$-statistic value of 19.41 indicates that $\mathrm{TS}_{\mathrm{i}}$ is not a weak instrument.

Table 4 displays second-stage instrumental variable estimation of three measures of smoking prevalence: daily, nondaily, and daily + nondaily smokers. Years 2001 to 2005 are pooled together yielding 249 observations in total, with one missing observation in 2004 for Hawaii. Dichotomous variables for years 2002, 2003, 2004 and 2005 are included to determine if intercepts differ for each year and these dummies are multiplied by price variables to form interactive dummies to determine if coefficients on cigarette price variables differ between those same years. Values for DUM2002 $2_{\mathrm{i}}$ are set equal to 1 for observations in 2002, and 0 otherwise, and so forth for DUM2003 ${ }_{i}$,

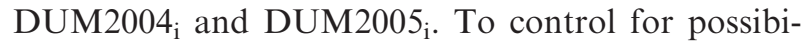
lity of differential variance by size of state, equations are estimated with SEs and variances that use White's (1980) covariance estimator. Coefficient covariances are calculated in presence of heteroskedasticity of unknown form.

The first column shows that cigarette prices exert significant and negative effects on daily prevalence with an estimated elasticity coefficient of -0.43 . Other significance influences are bachelor's degree (negative, as expected) and percent of population that are Mormon (negative, as expected). No effects are found for per capita income, median age, unemployment or tobacco control spending. All dummy variables - simple intercept shifters or interactive cigarette price slope shifters - exert no effects on daily prevalence thus indicating that neither differs over time.

The second column shows that prices do not exert significant effects on nondaily prevalence, which differs from the significant and negative effect in the daily prevalence equation. Three influences are significant: bachelor's degree (negative), median age (negative) and Mormon (negative). The sign on median age is positive, as hypothesized. All dummy variables for the various years remain insignificant. The third column shows that prices exert significant and negative influences on daily + nondaily prevalence, along with income (positive), bachelor's degree (negative), unemployment (positive) and Mormon (negative).

In sum, the results of Table 4 show that cigarette prices exert significant and negative influences daily and daily + nondaily prevalence, and that bachelor's degree and Mormon variables exert negative and significant influences on all measures of prevalence. Median age and income variables exert significant influences at times. No effects on any measure of prevalence are determined for tobacco control spending. Dummy variables indicate no significant shifts in intercepts or interactive effects with cigarette prices between years.

Table 5 displays estimations of prevalence measures that include interaction terms between years and tobacco control spending to determine whether effects from spending differ between years in our pooled sample. Interactive terms between year dummies and cigarette prices are excluded for simplicity given their previous lack of significance. Daily prevalence estimations are displayed in column one. Estimated price elasticity is again inelastic with a coefficient of -0.39 , slightly lower than previous estimation of -0.41 . Significant influences with the same signs remain for bachelor's degree and Mormon variables. No significant effects again are found for unemployment or tobacco control spending, but per capita income is now (weakly) statistically significant at the $10 \%$ level. Year dummy variables exert significant and negative effects for years 2004 and 2005. Only the interactive tobacco control spending slope shifter in 2004 is found to exert a significant effect, and because its sign is positive, this indicates

\footnotetext{
${ }^{26}$ First-stage estimates of coefficients ( $t$-statistics) are: $-25.36(3.22)+4.31$ (3.02) PRICE $-0.0002(3.34)$ INCOME + 0.06 (1.23) COLLEGE + 0.17 (1.64) AGE -0.32 (1.92) UNEMPLOYMENT + 0.02 (0.96) MORMON + 0.08 (4.41) TS -0.42 (0.81) DUM2002 + 0.54 (1.00) DUM2003 + 0.67 (1.26) DUM2004 + 0.66 (1.25) DUM2005.
}

${ }^{27}$ See Stock and Watson (2003). 
Table 4. Effects of price on smoking prevalence estimated coefficients ( $t$-statistics in parentheses)

\begin{tabular}{|c|c|c|c|c|c|c|}
\hline \multirow[b]{3}{*}{$\log ($ PRICE) } & \multicolumn{2}{|l|}{ (1) } & \multicolumn{2}{|l|}{ (2) } & \multicolumn{2}{|l|}{ (3) } \\
\hline & \multicolumn{2}{|l|}{ Daily } & \multicolumn{2}{|l|}{ Nondaily } & \multicolumn{2}{|c|}{ Daily + nondaily } \\
\hline & $-0.4320^{\mathrm{b}}$ & $(-2.30)$ & 0.1473 & $(0.72)$ & $-0.2948^{b}$ & $(2.04)$ \\
\hline Per capita income & $5.6 \mathrm{E}-06$ & $(1.49)$ & 4.9E-06 & $(1.22)$ & $5.3 \mathrm{E}-06^{\mathrm{c}}$ & $(1.85)$ \\
\hline Bachelor's degree & $-0.0211^{\mathrm{a}}$ & (7.74) & $-0.0081^{\mathrm{a}}$ & $(2.75)$ & $-0.0182^{\mathrm{a}}$ & $(8.69)$ \\
\hline Median age & 0.0079 & (1.44) & $-0.0375^{\mathrm{a}}$ & $(6.29)$ & -0.0032 & $(0.77)$ \\
\hline Unemployment & 0.0129 & $(1.46)$ & 0.0113 & (1.18) & $0.0127^{\mathrm{c}}$ & $(1.87)$ \\
\hline Mormon & $-0.0098^{\mathrm{a}}$ & $(8.47)$ & $-0.0142^{\mathrm{a}}$ & $(11.35)$ & $-0.0109^{\mathrm{a}}$ & (12.36) \\
\hline Spending & 0.0097 & $(0.90)$ & -0.0002 & $(0.02)$ & 0.0068 & $(0.82)$ \\
\hline Dum2002 & 0.0071 & $(0.90)$ & 0.3728 & $(0.29)$ & 0.1852 & $(0.20)$ \\
\hline Dum2003 & -0.0026 & $(0.01)$ & 1.0763 & $(0.84)$ & 0.2805 & $(0.31)$ \\
\hline Dum2004 & -0.8230 & $(0.70)$ & -0.2429 & $(0.19)$ & -0.7547 & $(0.84)$ \\
\hline Dum2005 & -1.5715 & $(1.37)$ & 1.1034 & $(0.89)$ & -0.9721 & (1.11) \\
\hline Dum2002 * $\log ($ PRICE $)$ & 0.0120 & $(0.06)$ & -0.0836 & $(0.38)$ & -0.0257 & $(0.17)$ \\
\hline Dum $2003 * \log ($ PRICE $)$ & 0.0046 & $(0.02)$ & -0.1958 & $(0.91)$ & -0.0472 & $(0.31)$ \\
\hline Dum2004 * $\log ($ PRICE $)$ & 0.1284 & $(0.65)$ & 0.0384 & $(0.18)$ & 0.1190 & $(0.79)$ \\
\hline Dum $2005 * \log ($ PRICE $)$ & 0.2500 & $(1.30)$ & -0.1866 & $(0.89)$ & 0.1524 & $(1.03)$ \\
\hline Intercept & $5.4340^{\mathrm{a}}$ & $(4.91)$ & $2.2258^{\mathrm{c}}$ & $(1.85)$ & $5.2483^{\mathrm{a}}$ & $(6.19)$ \\
\hline $\mathrm{SE}$ of regression & 0.1143 & & 0.1241 & & 0.0877 & \\
\hline Observations & 249 & & 249 & & 249 & \\
\hline$R^{2}$ (adjusted) & 0.65 & & 0.43 & & 0.69 & \\
\hline Mean dependent variable & 2.82 & & 1.65 & & 3.09 & \\
\hline
\end{tabular}

Note: ${ }^{\mathrm{a}, \mathrm{b}, \mathrm{c}}$ Significant (two-tailed test) at $1 \%, 5 \%$ and $10 \%$ levels, respectively.

Table 5. Effects of tobacco control spending on smoking prevalence estimated coefficients (t-statistics in parentheses)

\begin{tabular}{|c|c|c|c|c|c|c|}
\hline \multirow[b]{3}{*}{$\log$ (PRICE) } & \multicolumn{2}{|l|}{ (1) } & \multicolumn{2}{|l|}{ (2) } & \multicolumn{2}{|l|}{ (3) } \\
\hline & \multicolumn{2}{|l|}{ Daily } & \multicolumn{2}{|l|}{ Nondaily } & \multicolumn{2}{|c|}{ Daily + nondaily } \\
\hline & $-0.3926^{\mathrm{a}}$ & $(4.13)$ & 0.0762 & $(0.72)$ & $-0.2807^{\mathrm{a}}$ & $(3.83)$ \\
\hline Per capita income & $6.5 \mathrm{E}-06^{\mathrm{c}}$ & $(1.76)$ & 4.7E-06 & $(1.14)$ & $5.9 \mathrm{E}-06^{\mathrm{b}}$ & $(2.08)$ \\
\hline Bachelor's degree & $-0.0212^{\mathrm{a}}$ & (7.96) & $-0.0084^{\mathrm{a}}$ & $(2.83)$ & $-0.0183^{\mathrm{a}}$ & $(8.91)$ \\
\hline Median age & 0.0055 & $(0.99)$ & $-0.0366^{\mathrm{a}}$ & $(5.93)$ & -0.0049 & $(0.15)$ \\
\hline Unemployment & 0.0135 & $(1.57)$ & 0.0089 & $(0.93)$ & $0.0125^{\mathrm{c}}$ & $(1.88)$ \\
\hline Mormon & $-0.0102^{\mathrm{a}}$ & (8.94) & $-0.0141^{\mathrm{a}}$ & (11.13) & $-0.0112^{\mathrm{a}}$ & $(2.80)$ \\
\hline Spending & 0.0037 & $(0.26)$ & 0.0015 & $(0.09)$ & 0.0025 & $(0.23)$ \\
\hline Dum2002 & 0.0824 & $(1.58)$ & $-0.1373^{\mathrm{b}}$ & $(2.37)$ & 0.0313 & $(0.78)$ \\
\hline Dum 2003 & -0.0012 & $(0.02)$ & -0.0076 & $(0.11)$ & -0.0038 & $(0.08)$ \\
\hline Dum2004 & $-0.1623^{\mathrm{b}}$ & $(2.55)$ & 0.0009 & $(0.01)$ & $-0.1231^{\mathrm{b}}$ & $(2.50)$ \\
\hline Dum2005 & $-0.1557^{\mathrm{b}}$ & $(2.55)$ & 0.0047 & $(0.07)$ & $-0.1154^{\mathrm{b}}$ & $(2.46)$ \\
\hline Dum $2002 *$ Spending & -0.0025 & $(0.14)$ & 0.0138 & $(0.32)$ & -0.0002 & $(0.01)$ \\
\hline Dum $2003 *$ Spending & 0.0086 & $(0.42)$ & -0.0278 & $(1.22)$ & 0.0008 & $(0.05)$ \\
\hline Dum2004* Spending & $0.0362^{\mathrm{c}}$ & 1.74 & -0.0024 & $(0.10)$ & $0.0274^{\mathrm{c}}$ & $(1.71)$ \\
\hline Dum2005* Spending & 0.0274 & $(1.37)$ & -0.0050 & $(0.22)$ & 0.0194 & $(1.26)$ \\
\hline Intercept & $5.2740^{\mathrm{a}}$ & $(9.40)$ & $2.6327^{\mathrm{a}}$ & $(4.21)$ & $5.2191^{\mathrm{a}}$ & $(12.08)$ \\
\hline $\mathrm{SE}$ of regression & 0.1114 & & 0.1242 & & 0.0858 & \\
\hline Observations & 249 & & 249 & & 249 & \\
\hline$R^{2}$ (adjusted) & 0.66 & & 0.43 & & 0.71 & \\
\hline Mean dependent variable & 2.82 & & 1.66 & & 3.10 & \\
\hline
\end{tabular}

Note: ${ }^{\text {a, b, c }}$ Significant (two-tailed test) at $1 \%, 5 \%$ and $10 \%$ levels, respectively.

that tobacco control spending exerted a positive effect on daily prevalence. Economic significance of this effect, however, is questionable given significance at only the $10 \%$ level.
Column two displays estimates of nondaily prevalence. As before, prices do not exert significant effects, and bachelor's degree, median age and Mormon are significant. The only significant time 
Table 6. Effects of tobacco control spending on smoking prevalence: estimated coefficients ( $t$-statistics in parentheses)

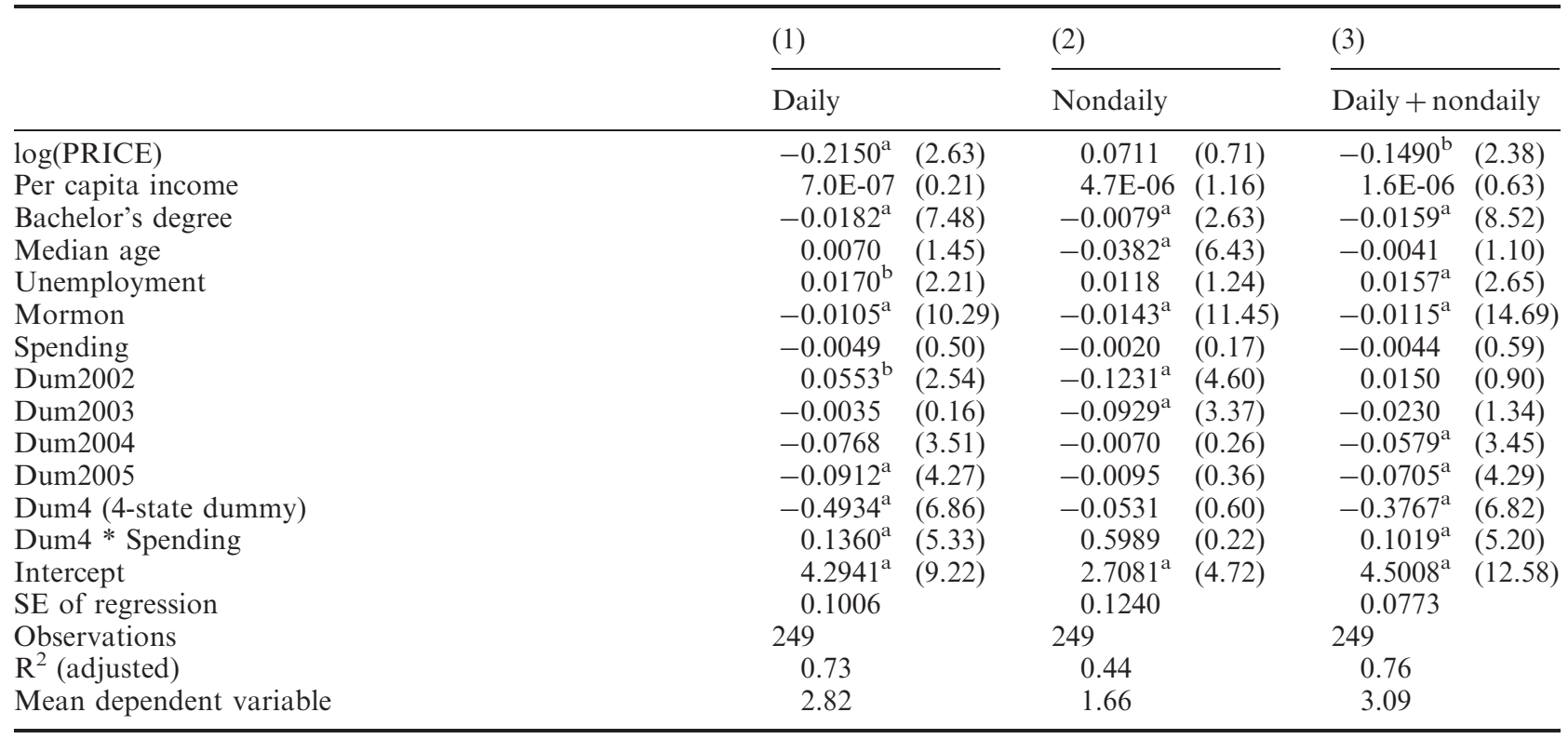

Note: ${ }^{\text {a, b, c }}$ Significant (two-tailed test) at $1 \%, 5 \%$ and $10 \%$ levels, respectively.

dummy is that of year 2002 and indicates that the base level of nondaily prevalence is significantly lower during that year. Tobacco control spending continues to exert insignificant influences. The third column shows that prices exert significant influences on daily + nondaily prevalence, consistent with results in the previous table. Significant influences are determined for bachelor's degree, unemployment, Mormon and income variables. Tobacco control spending continues to exert no significant effect. Year dummy variables exert significant and negative effects for years 2004 and 2005, thus indicating that base levels of daily + nondaily prevalence are significantly lower in these two years. Consistent with estimation in column one, only the interactive tobacco control spending slope shifter in 2004 exerts a significant (positive) effect, but again, it is weakly significant at the $10 \%$ level.

Table 6 displays estimations of prevalence measures that control for the four states with long and active histories of tobacco control programmes (Arizona, California, Massachusetts and Oregon) through a dummy variable for these four states ( $=1$ if one of these four states; $=0$ otherwise) and an interactive term between this four-state dummy and tobacco control spending to determine if spending in these four states impact prevalence differently than states without long and active histories. As discussed, this interactive term controls for the possibility that spending prior to 2001 exerts effects in later years and allows for the possibility that many years of funding are necessary before significant effects on prevalence arise.

Results in column one indicate that prices (negative), bachelor's degree (negative), unemployment (positive), Mormon (negative) and intercept dummies for year 2002 (positive), and year 2005 (negative) exert significant effects on daily prevalence. Tobacco control spending, by itself, continues to exert no significant influence. The four-state dummy exerts a significant and negative effect thus indicating that base levels of prevalence in these four states are lower than in the other states. However, interaction between the four-state dummy and the tobacco control spending variable indicates a positive and significant effect on prevalence. That is, while an additional dollar on tobacco control yields no significant influence on daily prevalence in all states taken together, a positive and significant influence is found when we isolate the four states with longstanding tobacco control programes. ${ }^{28}$ That is, an additional dollar is determined to raise daily prevalence, which is contrary to expectations. The estimated coefficient on this interaction variable is 0.1360 which yields the following interpretation: a change in tobacco control spending by $\$ 1$ dollar per

\footnotetext{
${ }^{28}$ As discussed previously, percent of the voting-age population voting in Presidential elections was also considered as an alternative instrument. Estimations using this instrument yielded nearly identical coefficients of the same significance on this interaction variable between tobacco control spending and the four states with long-standing programmes.
} 
capita, is associated with a $14 \%(100 * .1360)$ change in daily prevalence.

Column two shows that bachelor's degree (negative), median age (negative), Mormon (negative), and intercept dummies for years 2002 and 2003 (both negative) exert significant effects on non-daily prevalence. Neither the four-state dummy, nor its interaction with tobacco-control spending, exert significant effects. Column three shows that prices (negative), bachelor's degree (negative), unemployment (positive), Mormon (negative), and intercept dummies for year 2004 (negative) and year 2005 (negative) exert significant effects on non-daily prevalence. The four-state dummy is significant and negative thus indicating that base levels of daily + non-daily prevalence are lower than in states with long histories of tobacco control. Similar to column one, interaction of the four-state dummy with tobacco control spending exerts significant and positive influences on this measure of prevalence and suggests that a $\$ 1$ dollar per capita change is associated with a $10 \%(100 \times 0.1019)$ change in daily prevalence.

\section{Conclusion}

This study finds no evidence that tobacco control spending exerted significant effects on adult smoking prevalence over years 2001 to 2005 in the 50 states. These results are inconsistent with much of the existing literature, but are consistent with a few recent articles that examine later years of tobacco funding. Cigarette prices are found to lower daily prevalence, but exert no effect on nondaily prevalence. Higher taxes then would appear to exert no effect on nondaily, or more casual smokers as they are unresponsive to price. Prices are also usually found to exert inverse influences on the two prevalence measures summed together, which is CDC's preferred measure of prevalence. This result suggests that higher taxes exert health benefits by raising prices, which then results in lower prevalence. ${ }^{29}$ But, this study also indicates that tobacco control programmes do not influence prevalence. ${ }^{30}$

Effects of tobacco control spending on prevalence are found to differ as a group between the four states with long-standing tobacco control programmes
(Arizona, California, Massachusetts, Oregon) and all 50 states together. While base levels of daily and daily + nondaily prevalence are significantly lower in these four states, an additional dollar of tobacco control spending is determined to raise prevalence in these four states, but not in all 50 states together. That is, while spending does not influence prevalence in all 50 states taken together, a positive influence is indicated when these four states are isolated through an interactive slope shifter variable. Per capita increases of $\$ 1$ are associated with 10 to $14 \%$ changes in prevalence. These findings are clearly contrary to conventional wisdom and deserve further investigation in future research. Perhaps a good starting point would be to question whether past efforts in these four states have led to very different group of smokers than in other states. As discussed, base levels of prevalence are significantly lower in these four states and, given their long-standing tobacco control programmes, it would be interesting to uncover what behavioural differences might exist between smokers in these four states when compared to all states, or perhaps differences in tobacco control programmes as well. There is no obvious reason to suggest that an additional dollar of tobacco control spending should exert the same effect on prevalence in states with dissimilar histories of past tobacco control activity or dissimilar populations of smokers.

Several other reasons may explain why results conflict with previous research. As discussed, studies showing that spending is inversely related to smoking either examined two states (California and Massachusetts) with long-standing tobacco control programmes without controlling for other possible factors and/or examined periods in which many states in their samples did not actively fund programmes. This article examines recent data with more actively funded programmes across a wide array of states. Evidence in this article may also indicate that past abilities to reduce smoking may have been eroded over time. It is possible, for example, that early efforts were more productive at lowering smoking, but, at the margin, similar success becomes more difficult, or even leads to opposite behavioural effects, as fewer smokers are willing to lower consumption. Finally, past studies may also have been biased towards finding that tobacco control programmes lowered smoking because they selectively focused on states with long-standing programmes and did not control

\footnotetext{
${ }^{29}$ For example, Escario and Molina (2004) find that, based on a sample of 12 EU countries over 1983 to 1993 , a $10 \%$ surtax on tobacco would reduce lung cancer mortality by $1.2 \%$ in the first year.

${ }^{30}$ Goel (2007) examines state-level US data of quitting behaviour by smokers and shows that, while workplace smoking restrictions do not affect behaviour, quite decisions are significantly influenced by cigarette prices and home smoking restrictions.
} 
for the possibility that these states generously fund tobacco control because they have many citizens interested in lowering smoking, or more effectively use public monies to lower smoking or have more active and well-organized anti-smoking organizations than other states. The present article dealt with this possibility that tobacco control spending was endogenous through instrumental variable estimation. Further research should continue investigation of this issue with additional data and controls for endogeneity.

\section{References}

American Lung Association, State of Tobacco Control. (2003) http://lungaction.org/reports/key304.html.

Americans for Nonsmokers' Rights. (2006) Detailed List of Smoking Laws, Berkeley, CA.

Biener, L., Harris, J. E. and Hamilton, W. (2000) Impact of the Massachusetts Tobacco Control Programme: population based trend analysis, $B M J$, 321, 351-4.

Boyes, W. J. and Marlow, M. L. (1996) The public demand for smoking bans, Public Choice, 88, 57-67.

Centers for Disease Control, \& Prevention (CDC) (2001) Tobacco control state highlights 2001: impact and opportunity, Department of Health and Human Services, Centers for Disease Control and Prevention, National Center for Chronic Disease Prevention and Health Promotion, Office on Smoking and Health, Atlanta, GA.

Centers for Disease Control, and Prevention (CDC) (2002) Tobacco control state highlights 2002: impact and opportunity, Department of Health and Human Services, Centers for Disease Control and Prevention, National Center for Chronic Disease Prevention and Health Promotion, Office on Smoking and Health, Atlanta, GA.

Centers for Disease Control and Prevention (CDC) (2006) Behavioral Risk Factor Surveillance System Survey Data, U.S. Department of Health and Human Services, Centers for Disease Control and Prevention, Atlanta, Georgia.

Dunham, J. and Marlow, M. L. (2003) The economic incidence of smoking laws, Applied Economics, 35, 1935-42.

Escario, J. J. and Molina, J. A. (2004) Will a special tax on tobacco reduce lung cancer mortality? Evidence for EU countries, Applied Economics, 36, 1717-22.

Fareelly, M. C., Evans, W. N. and Sfekas, A. E. S. (1999) The impact of workplace smoking bans: results from a national survey, Tobacco Control, 8, 272-7.

Farrelly, M. C., Pechacek, T. F. and Chaloupka, F. J. (2003) The impact of Tobacco Control Program expenditures on aggregate cigarette sales: 1981-2000, Journal of Health Economics, 22, 843-59.

Goel, R. K. and Nelson, M. A. (2005) Tobacco policy and tobacco use: differences across tobacco types, gender and age, Applied Economics, 37, 765-71.

Goel, R. K. (2007) Costs of smoking and attempts to quit, Applied Economics, 39, 853-7.
Gross, C. P., Soffer, B., Bach, P. B., Rajkumar, R. and Forman, H. P. (2003) State expenditures for tobaccocontrol programs and the tobacco settlement, New England Journal of Medicine, 347, 1080-6.

Hu, T.-W., Sung, H.-Y. S and Keeler, T. E. (1995a) The State Antismoking Campaign and the industry response: the effects of advertising on cigarette consumption in California, American Economic Review, Papers and Proceedings, 85, 85-90.

Hu, T.-W., Sung, H.-Y. S. and Keeler, T. E. (1995b) Reducing cigarette consumption in California: tobacco taxes vs. an anti-smoking media campaign, American Journal of Public Health, 85, 1218-22.

Ibrahaim, J. K and Glantz, S. A. (2003) Tobacco policymaking in California 2001-2003: no longer finishing first, Center for Tobacco-control Research and Education, University of California, San Francisco.

Keeler, T. E., Hu, T.-W., Ong, M. and Sung, H.-Y. (2004) The US National Tobacco Settlement: the effects of advertising and price changes on cigarette consumption, Applied Economics, 36, 1623-29.

Koh, H. K., Judges, C. M., Robbins, H., Celebucki, C. C., Walker, D. K. and Connlly, G. N. (2005) The first decade of the Massachusetts Tobacco Control Program, Public Health Reports, 120, 482-95.

Luccasasen, R. A., Coats, R. M. and Karahan, G. (2005) Cigarette smuggling mitigates the public health benefits of cigarette taxes, Applied Economics Letters, 12, 769-73.

Lye, J. N. and Hirschberg, J. (2004) Alcohol consumption, smoking and wages, Applied Economics, 36, 1807-17.

Madden, D. (2007) Tobacco taxes and starting and quitting smoking: does the effect differ by education?, Applied Economics, 39, 613-27.

Manley, M. W., Pierce, J. P., Gilpin, E. A., Rosbrook, B., Berry, C. and Wun, L. (1997) Impact of the American Stop Intervention Study on cigarette consumption, Tobacco Control, 6(Suppl. 2), S12-6.

Marlow, M. L. (2006) Tobacco control programs and tobacco consumption, Cato Journal, 26, 573-91.

Marlow, M. L. (2007) Determinants of state tobaccocontrol expenditures, Applied Economics, 2007 (forthcoming).

Orzechowski, W. and Walker, R. C. (2006) The Tax Burden on Tobacco: Historical Compilation 2006, Arlington, VA.

Pierce, J. P., Gilpin, E. A., Emery, S. L., White, M. M., Rosbrook, M. and Berry, C. (1998) Has the California Tobacco Control Program reduced smoking?, Journal of the American Medical Association, 280, 893-9.

Reinhardt, F. S. and Giles, D. E. A. (2001) Are cigarette bans really good economic policy?, Applied Economics, 33, 1365-8.

Robbins, H., Krakow, M. and Warner, D. (2002) Adult Smoking Intervention Programmes in Massachusetts: a comprehensive approach with promising results, Tobacco Control, 11 (Suppl. II), ii4-7.

Sharmistha, S. and Grabowski, R. (2003) How effective is public health expenditure in improving overall health? A cross-country analysis, Applied Economics, 35, 835-45.

Soldz, S., Clark, T. W., Stewart, E., Celebucki, C. and Walker, D. (2002) Decreased youth tobacco use in Massachusetts 1996-1999: evidence of tobacco control effectiveness, Tobacco Control, 11(Suppl. II), ii14-9. 
Stevenson, T. P. and Shughart II, W. F. (2006) Smoke and mirrors: the political economy of the tobacco settlements, Public Finance Review, 34, 712-30.

Stehr, M. (2005) Cigarette tax avoidance and evasion, Journal of Health Economics, 24, 277-97.

Statistical Abstract of the United States. (2007) U.S. Department of Commerce, Washington, DC.

Stock, J. H. and Watson, M. W. (2003) Introduction to econometrics. Addison Wesley, Boston.

Tauras, J. A. and Chaloupka, F. J. (2004) Impact of tobacco control spending and tobacco control policies on adolescents' attitudes and beliefs about cigarette smoking, Evidence-Based Preventative Medicine, 1, 111-20.

Tauras, J. A., Chaloupka, F. J., Forrelly, M. C., Giovino, G. A., Wakefield, M., Johnston, J. D., O’Malley, P. M., Kloska, D. D. and Pechacek, T. F. (2005) State tobacco control spending and youth smoking, American Journal of Public Health, 95, 338- 44.

Tauras, J. A. (2006) Smoke-free air laws, cigarette prices, and adult cigarette demand, Economic Inquiry, 44, $333-42$.
Tauras, J., Powell, L., Chaloupka, F. and Ross, H. (2007) The demand for smokeless tobacco among male high school students in the United States: the impact of taxes, prices and policies, Applied Economics, 39, $31-41$.

Wan, J. (2006) Cigarette tax revenues and tobacco control in Japan, Applied Economics, 38, 1663-75.

Weintraub, J. M. and Hamilton, W. L. (2002) Trends in prevalence of current smoking, Massachusetts and states without Tobacco Control Programmes, 1990-1999, Tobacco Control, 11 (Suppl. II), iI8-ii13.

White, H. (1980) A heteroscedasticity-consistent covariance matrix and a direct test for heteroscedasticity, Econometrica, 48, 817-38.

Yen, S. T. (2005) Zero observations and gender differences in cigarette consumption, Applied Economics, 37, 1839-49.

Yuanliang, B. and Zongyi, Z. (2005) Aggregate cigarette demand and regional differences in China, Applied Economics, 37, 2523-8. 